\title{
Análise via Elementos Finitos da Interface Aço- Concreto em Pisos Mistos de Pequena Altura
}

\author{
Finite Element Analysis of Steel-Concrete Interface in Slim Floor Composite Beams
}

\author{
Flávio Teixeira de Souza ${ }^{\mathbf{1}, 3}$ (D) orcid.org/0000-0003-3261-9089 \\ Lorena Cristine Soares ${ }^{\mathbf{2}, 3}$ (D) orcid.org/0000-0002-3787-5535
}

\section{Geraldo Donizetti de Paula ${ }^{2,3}$ orcid.org/0000-0002-4213-7473}

\footnotetext{
${ }^{1}$ Instituto Federal de Minas Gerais, Campus Ouro Preto - MG, Brasil.

2 Universidade Federal de Ouro Preto - MG, Brasil.

3 Mestrado Profissional em Engenharia das Construções - MECON/DECIV/UFOP.
}

E-mail do autor principal: Flávio Souza flavio.souza@ifmg.edu.br

\section{Resumo}

O sistema de pisos mistos de pequena altura - Slim Floor - é uma viga mista onde a laje de concreto é apoiada sobre a mesa inferior do perfil metálico, envolvendo totalmente a viga. Além do ganho de resistência proporcionado pelo sistema misto, esta disposição aumenta a proteção do perfil metálico ao fogo e, principalmente, leva a uma redução considerável da altura da associação entre a laje e o perfil metálico. No entanto, as condições de interface entre os materiais devem ser analisadas, pois, nestes sistemas, em geral não se usam conectores de cisalhamento. Este trabalho faz a análise da representação da interface aço-concreto em sistemas Slim Floor em simulação em elementos finitos. Utilizando o software ANSYS, esta interface foi modelada de duas formas: com elementos de mola e com elementos de contato, considerando-se adequadamente as propriedades do aço e do concreto. Os resultados foram comparados com resultados experimentais disponíveis na literatura, indicando a viabilidade de ambas as estratégias para a simulação das estruturas mistas.

Palavras-Chave: Estruturas mistas de aço-concreto; Pisos mistos de pequena altura; Método dos Elementos Finitos.

\begin{abstract}
Slim Floor Systems are composite beams where concrete slab is placed under steel I beam bottom flange, and the concrete covers the whole beam. It increases considerably the system's bending resistance, fire resistance and reduces the composite beam high. Instead, the connection between the steel and the concrete must be considered carefully, because shear connectors usually are not used in Slim Floor systems. This research analyzed connection steel-concrete by finite element analysis. This interface was simulated using springs and contact elements in software ANSYS, considering adequately steel and concrete properties. Comparison with experimental data available in literature indicated that both methods are suitable to simulate steel-concrete interaction in composite structures.
\end{abstract}

Key-words: Steel-concrete composite structures; Slim Floor; Finite Element Method. 


\section{Introdução}

As estruturas mistas têm o objetivo de aproveitar as vantagens de cada um dos elementos utilizados (aço e concreto), não apenas em termos estruturais, mas também em aspectos construtivos, funcionais e estéticos. O funcionamento das estruturas mistas de aço-concreto é garantido de maneira mais frequente através de interação mecânica por conectores de cisalhamento, soldados à viga metálica e embutidos na laje de concreto.

Em um piso misto convencional, a laje de concreto é posicionada sobre o flange superior da viga de aço. Desta forma, uma das características principais desse sistema é sua elevada altura total, decorrente da soma da altura da viga e da espessura da laje de concreto, o que pode ocasionar uma limitação do pédireito do pavimento. Por outro lado, o sistema de pavimento misto de pequena altura, Slim Floor, entre outros aspectos, visa a redução dessa altura apoiando a laje sobre o flange inferior da viga de aço, como apresentado na Figura 1. Além disso, no cenário atual das construções metálicas e mistas, tem crescido significativamente a importância do projeto estrutural que apresente maior durabilidade em condições de incêndio, o que faz com que o sistema Slim Floor seja bastante atrativo devido à sua capacidade resistente ao fogo, visto que as vigas metálicas estão parcialmente revestidas pelo concreto.

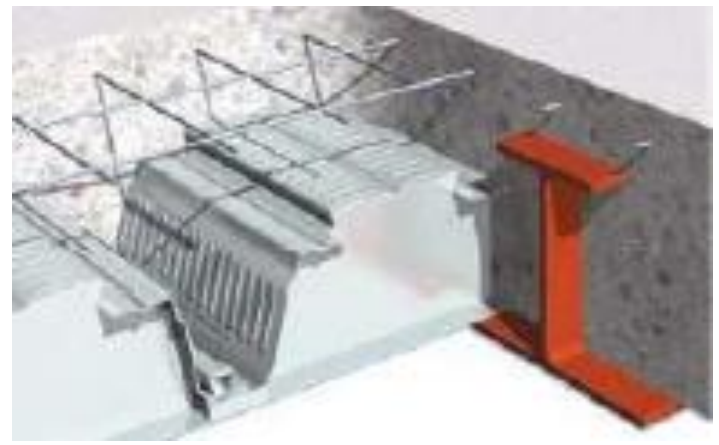

Figura 1: Perfil ASB constituindo o sistema Slimdek. Fonte: Ramos [1].

A utilização de estruturas mistas no Brasil deu-se, inicialmente, utilizando-se de manuais e normas internacionais para construção de alguns edifícios e pontes de pequeno vão entre as décadas de 1950 e 1960. Entre 1970 e início dos anos de 1980, foi notada uma estagnação da utilização dos sistemas mistos de aço-concreto no país. Isso possivelmente ocorreu devido à opção ao uso de estruturas e métodos convencionais, situação que ainda é verificada atualmente, e à necessidade de profissionais qualificados em seu projeto e execução (MALITE [2]).

A norma NBR 8800 ABNT de 2008 [3] abrange o comportamento e critérios de dimensionamento para vigas, pilares e lajes mistas de aço-concreto, sem, no entanto, abordar explicitamente o sistema misto de pequena altura. Desta forma, destaca-se a importância dos estudos das estruturas mistas e dos pavimentos mistos de pequena altura em relação ao seu comportamento durante toda a sua vida útil, para melhora das técnicas construtivas e o consequente aperfeiçoamento dos princípios de projeto deste sistema, bem como para possibilitar a elaboração de normas para o sistema Slim Floor (KOCHEN [4]).

No caso das estruturas Slim Floor, quando não prevista a utilização de conectores de cisalhamento, se torna necessária a consideração da interação entre o aço e o concreto através do atrito gerado por ranhuras que podem ser dispostas no perfil metálico, e ainda outras formas de ativação desta aderência (HOU [5]), pois neste arranjo, o perfil metálico tem uma região de contato muito superior quando comparada aos sistemas mistos tradicionais.

O modelo objeto de validação para os estudos em Slim Floor do presente trabalho foi desenvolvido experimentalmente pelo Steel Construction Institute SCI e British Steel (atual Tata Steel) no Reino Unido, através de ensaios com perfis do tipo Asymmetric Slim Flor Beam - ASB, ligados a uma laje mista (LAWSON et al. [6]). Esse estudo foi realizado para determinar o momento fletor resistente da viga mista e a tensão última de aderência na interface aço-concreto.

Paes [7] apresentou um estudo do sistema Slim Floor constituído de vigas com ranhuras dispostas na aba superior do perfil metálico, via Métodos dos Elementos Finitos. Analisou os modelos SCI - 280 ASB, com as dimensões demonstradas na Figura 2, e 300 ASB, obtendo resultados muito próximos aos resultados experimentais. Considerou em seu estudo as propriedades do concreto, tais como a fluência e retração. 


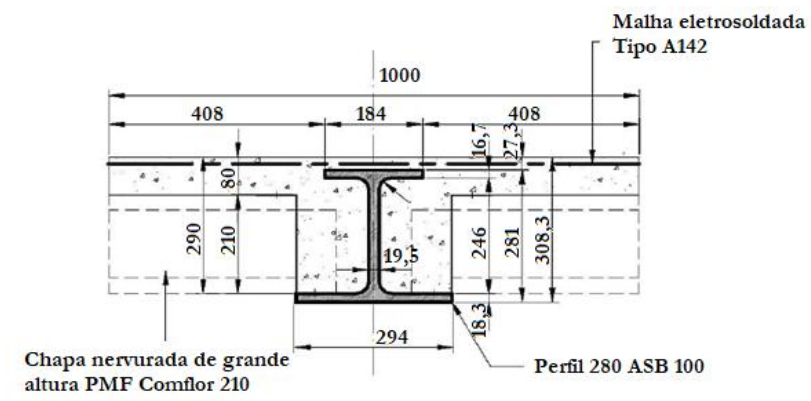

Figura 2. Dimensões do modelo. Fonte: Lawson et al. [6] apud Paes [7].

Para representação da interface aço-concreto, Paes [7] realizou em seu estudo uma reinterpretação dos estudos feitos por Leskelä e Hopia [8], em que foram analisados quatro diferentes tipos de conexão de cisalhamento para estruturas de Slim Floor: alma lisa; alma com ranhuras superficiais; alma lisa com barras de aço passantes e, por fim, alma com ranhuras superficiais e barras de aço passantes. Como pode ser visto em outros trabalhos sobre modelagens numéricas de sistemas Slim Floor, as principais dificuldades encontradas remetem à representação das várias interfaces entre o aço e o concreto, bem como o comportamento do concreto em si, e ainda, as diferentes formas em ativar este comportamento misto do aço e concreto (LAM [9]; CHEN [10]; SHEEHAM ET AL. [11]; SCHORR E KUHLMANN [12]; BALDASSINO ET AL. [13]; ROCHA E MUNAIAR NETO [14]).

A modelagem numérica permite maior possibilidade de estudos, sem a necessidade do elevado custo inerente à realização de ensaios experimentais. Este trabalho apresenta a análise de um sistema de piso misto de pequena altura via elementos finitos, no software ANSYS [15], com ênfase na atribuição das propriedades do concreto armado e nas possibilidades de implementação da interface aço-concreto, tendo como referência resultados experimentais disponíveis na literatura (LAWSON et al. [6]).

\section{Análise numérica}

A geometria do modelo foi feita a partir da geração dos volumes no ANSYS [15]. A malha de elementos finitos foi feita a partir dos volumes criados, buscando aliar a precisão e a eficiência computacional. A malha de elementos finitos é apresentada na Figura 3.

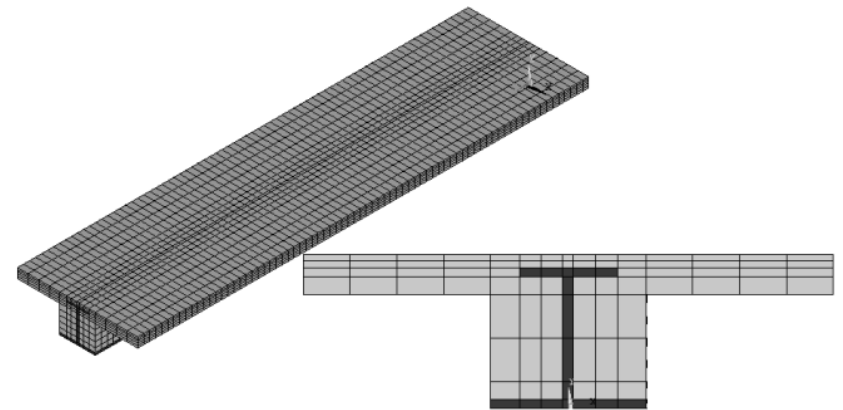

Figura 3. Malha de elementos finitos.

Os elementos finitos adotados nesta pesquisa pertencem à biblioteca interna do ANSYS [15]. O elemento utilizado para simular o comportamento do perfil metálico foi o SOLID186, com vinte nós, sendo três graus de liberdade por nó: translações nos eixos $x, y$ e $z$. Esse elemento é capaz de ser associado a materiais com comportamento não linear e ainda permite simular o comportamento plástico, além de outras características que não serão utilizadas para este estudo.

Para representação da laje de concreto, foi utilizado o elemento SOLID65, com oito nós, e três graus de liberdade em cada nó. Esse elemento é capaz de simular os esforços de tração e compressão, podendo ser visualizado inclusive o detalhamento dos primeiros pontos de fissuras ocorridas na laje. O elemento permite ainda a inclusão de armadura através de taxas. Tais armaduras podem ser dispostas em até três direções distintas. Neste trabalho, as armaduras da laje de concreto foram inseridas através de taxas, com suas propriedades mecânicas adicionadas como forma de constantes reais atribuídas ao elemento de concreto.

Foram utilizadas duas alternativas para a simulação da interface aço-concreto. Uma das alternativas, baseada no trabalho realizado por Paes [7], foi o elemento COMBIN39, que é um elemento de mola unidirecional que possui capacidade longitudinal ou torcional. Para sua opção longitudinal, utilizada neste trabalho, é um elemento de compressão-tração uniaxial com até três graus de liberdade por nó - translações nas direções $x$, y e z e grande capacidade de deslocamento. Para a utilização deste elemento de mola é necessário informar ao programa a relação de força versus deslizamento (PAES [7]), representando seu comportamento longitudinal, sendo os demais deslocamentos impedidos. Foram criados elementos de mola com rigidez à translação na direção longitudinal do modelo. $\mathrm{Em}$ todos os nós foi feito o acoplamento dos 
deslizamentos nas direções ortogonais ao eixo da estrutura para impedir o deslocamento de corpo rígido.

A outra alternativa foi a utilização de elementos de contato TARGE170 e CONTA173 para representar a interação na superfície de interface aço-concreto. Tais elementos podem ser utilizados em análises tridimensionais com contato tipo superfície-superfície, sendo o elemento TARGE170 definido para a superfície alvo, mais rígida, e o elemento CONTA173 para a superfície de contato, mais deformável (MARCONCIN [16]). Para representar a superfície correspondente ao concreto, foi utilizado o TARGE170, já para a superfície do perfil metálico, o CONTA173.

Para representação da interface aço-concreto através dos elementos de contato foram utilizados os valores adotados por Kotinda [17] para as regiões de encontro dos dois materiais, em que o perfil metálico possui superfície lisa, e, com a finalidade de melhorar a convergência do modelo, encontraram-se em Oliveira et al. [18] parâmetros importantes para representar a aderência entre o concreto e o aço.

Foram inseridos os valores do coeficiente de atrito $(\mu)$ e coesão (c), com escorregamento regido pela Lei de Coulomb, descritos através da equação (1), conforme proposto por Kotinda [17]. Ao se exceder a tensão cisalhante limite $\left(\mathrm{T}_{\mathrm{lim}}\right)$, ocorre o deslizamento entre os materiais. $O$ valor de $P$ é a tensão normal.

$$
T_{\text {lim }}=\mu \cdot P+C
$$

Os valores adotados foram coeficiente de atrito $(\mu)=0,40$, coesão $(c)=0,18 \mathrm{kN} / \mathrm{cm}^{2}$, coeficiente de penetração $($ FTOLN) $=0,01$, que, segundo Kotinda [17], refere-se a um valor mínimo de penetração para que o status do contato seja considerado como fechado. Oliveira et al. [18] apresentam ainda o parâmetro de fator de rigidez normal $F K N=0,1$, que segundo os autores, é o valor recomendado quando a deformação predominante for de flexão. O mesmo valor de FKN foi adotado para o fator de rigidez de tração $F K T=0,1$. Para representação da superfície onde existem as ranhuras no perfil metálico, com maior aderência entre os materiais, foram adotados os mesmos parâmetros, com a única alteração para coesão (c), em que foi utilizado o valor de 2,00 $\mathrm{kN} / \mathrm{cm}^{2}$. A Figura 4 apresenta os elementos de contato.

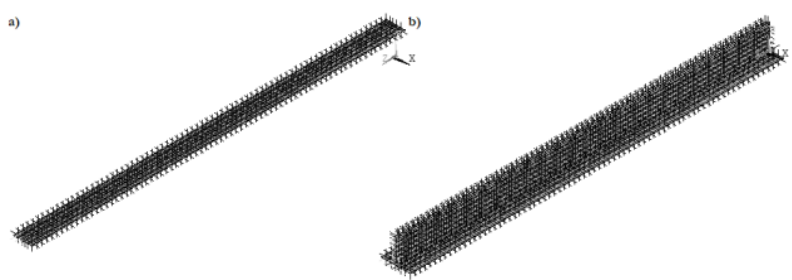

Figura 4. Interface aço-concreto com elementos targe170 e conta173. a) superfície com ranhuras superficiais no perfil metálico b) restante da interface lisa.

Para reduzir o tempo de análise computacional, foi utilizado o recurso de simetria (ANSYS [15]), que permite simular apenas a metade do sistema, sem impactos significativos nos resultados. Logo, modelou-se a metade do vão original de $7500 \mathrm{~mm}$, representado na Figura 5, adequando-se a aplicação de carga e as condições de contorno.

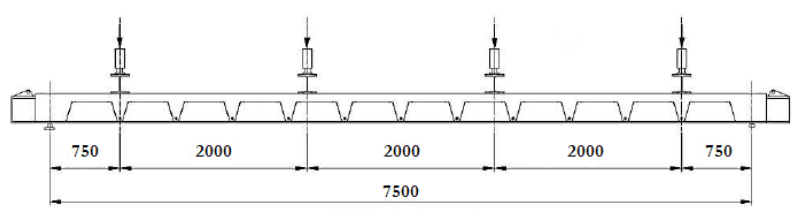

Figura 5. Dimensões do vão. Fonte: Lawson et al. [6] apud Paes [7].

O carregamento foi aplicado de modo incremental, devido à não linearidade física do material. Desta forma, o processamento foi subdividido em 100 etapas, para melhorar a convergência do modelo.

As condições de contorno empregadas, representadas na Figura 6, foram restrições à translação nas direções vertical e transversal, na região do apoio em uma das extremidades do modelo, no flange inferior do perfil metálico. A Figura 6 apresenta a malha de elementos finitos, as condições de contorno e o carregamento.

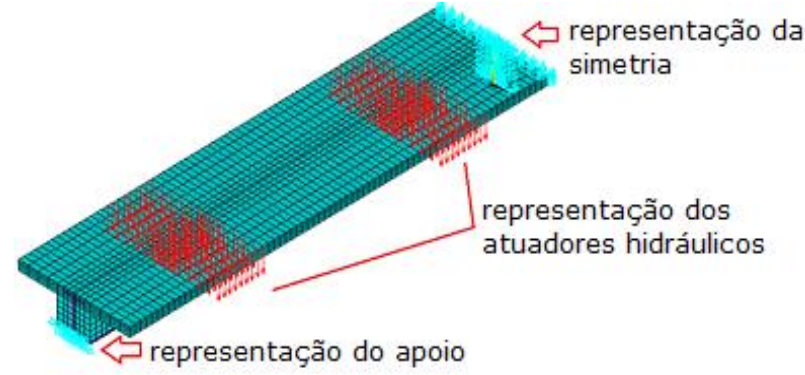

Figura 6. Condições de contorno e aplicação das cargas.

Foi adotado o modelo multilinear para o concreto. Os valores do módulo de elasticidade $\left(E_{c}\right)$, coeficiente de Poisson $(v)$, resistência à compressão $\left(f_{c k}\right)$ e resistência à tração $\left(f_{c t}\right)$ do concreto foram utilizados 
conforme descrito por Paes [7], que considera as características de um concreto de classe C35/40. Desta forma, foi adotado o valor de $\mathrm{E}_{\mathrm{c}}=35.000 \mathrm{MPa}$, $\mathrm{v}=0,20, \mathrm{f}_{\mathrm{ck}}=35 \mathrm{MPa}$ e $\mathrm{f}_{\mathrm{ct}}=3,23 \mathrm{MPa}$.

No que se refere ao comportamento às tensões de tração, foi utilizada uma relação constitutiva presente no ANSYS [15], concrete, baseado no modelo de Willan-Warnke. Os parâmetros necessários à sua utilização foram apresentados no trabalho de Paes [7] e alguns outros parâmetros permaneceram como prédefinidos pelo programa. Para o coeficiente de transferência de cisalhamento para fissura aberta, foi utilizado o valor de 0,3 ; para o coeficiente de transferência de cisalhamento para fissura fechada, o valor de 1,00; e para o coeficiente multiplicador de rigidez para condição fissurada na tração, foi utilizado o valor de 0,6.

Para obter a curva tensão-deformação para o concreto submetido à compressão uniaxial, são utilizadas as equações (2) e (3) (MODEL CODE [19]). Para que este comportamento seja ativado no ANSYS [15], é necessário desabilitar a função de compressão no modelo concrete, bastando para isso, informar o valor de -1 para a resistência à compressão no modelo concrete.

$$
\begin{aligned}
\frac{\sigma_{c}}{f_{c m}} & =\left(\frac{k \cdot \eta-\eta^{2}}{1+(k-2) \cdot \eta}\right) \\
f_{c m} & =f_{c k}+\Delta f \text { onde } \Delta f=8 M P a
\end{aligned}
$$

Onde:

$\eta=\varepsilon_{c} / \varepsilon_{c 1}, k=E_{c i} / E_{c 1}$

$\mathrm{f}_{\mathrm{cm}}=$ resistência média à compressão,

$\mathrm{f}_{\mathrm{ck}}=$ resistência característica à compressão do concreto,

$\varepsilon_{c}=$ deformação de compressão,

$\varepsilon_{c 1}=$ deformação na máxima tensão de compressão,

$k=$ número de plasticidade,

$E_{c i}=$ módulo de elasticidade inicial do concreto;

$E_{c 1}=$ módulo secante da origem do pico de tensão de compressão.

Para o perfil metálico, o aço utilizado no modelo experimental foi do tipo S355, com comportamento elasto-plástico perfeito, em um modelo constitutivo bilinear, com módulo de elasticidade $\left(E_{s}\right)$ de 210.000 MPa e coeficiente de Poisson (v), 0,30, e tensão de escoamento $\left(f_{y}\right)$ igual a $410 \mathrm{MPa}$.
Para as armaduras, representadas no modelo experimental por uma malha eletrosoldada A142, distribuída ao longo da parte superior da laje de concreto, são considerados os mesmos valores para o módulo de elasticidade e coeficiente de Poisson; já para tensão de escoamento, adotou-se o valor de 460 MPa. No modelo numérico, as armaduras são inseridas por meio de taxas, iguais em ambas direções, $A_{s x}=A_{s z}=1,42 \mathrm{~cm}^{2} / \mathrm{m}$.

\section{Resultados e discussões}

O modelo simulado, que possui sua representação da interface aço-concreto com os elementos de mola, COMBIN39, apresentou resultado que se aproxima do estudo experimental de Lawson et al. [6], como pode ser visto na Figura 7. Os valores numéricos se mostraram mais próximos aos resultados obtidos na análise experimental ao longo do trecho linear, e o momento fletor resistente foi de $732,48 \mathrm{kNm}$, para um deslocamento de $143 \mathrm{~mm}$. Desta forma, o resultado final do momento fletor, ficou $7,28 \%$ inferior ao resultado de Lawson et al. [6].

Com a utilização dos elementos de contato TARGE173 e CONTA170, os resultados numéricos ficaram próximos aos resultados experimentais, Figura 7, obtendo o valor de $746,22 \mathrm{kNm}$ para 0 momento fletor máximo, com uma flecha de $146 \mathrm{~mm}$, apresentando desta forma, uma diferença de 5,54\% do momento fletor máximo resistido em relação ao estudo experimental de Lawson et al. [6].

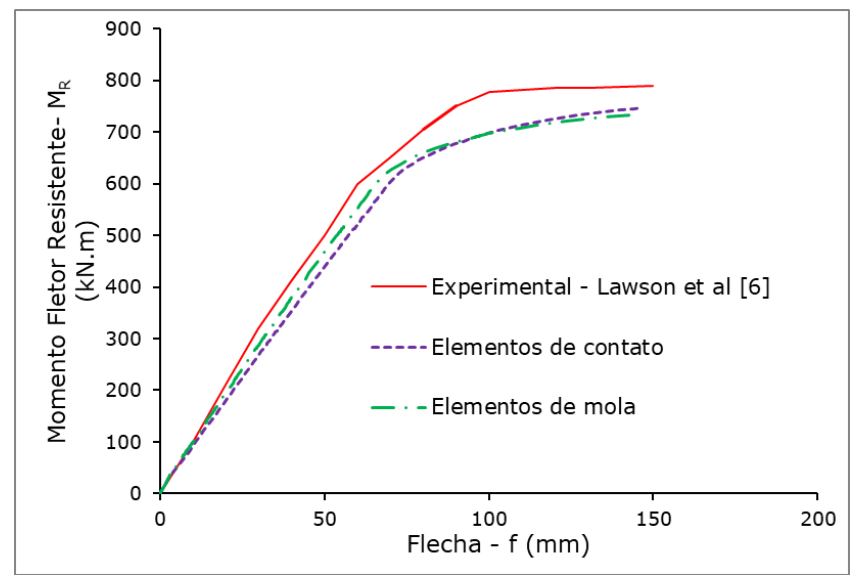

Figura 7. Diagrama de momento fletor - flecha para interface com molas e interface com targe e conta.

A Figura 8 traz a distribuição de tensões no perfil metálico e na laje de concreto, para o modelo em que foram utilizados os elementos de molas. Os resultados

DOI: $10.25286 /$ repa.v6i1.1450 
das tensões encontradas nos referidos materiais ficaram praticamente equivalentes nos dois modelos de interface apresentados, e dialogam com o resultado obtido por Paes [7] em sua pesquisa. Isso demonstra que os modelos constitutivos adotados para os materiais representam de forma satisfatória a estrutura. Na Figura 8 é possível observar ainda que, para o nível de carregamento próximo à carga máxima suportada pela viga, o perfil de aço se encontra plastificado na região mais solicitada do modelo, que representa o centro da viga, com tensões normais próximas ao valor do limite elástico do aço, de $\mathrm{f}_{\mathrm{y}}=410 \mathrm{MPa}$.
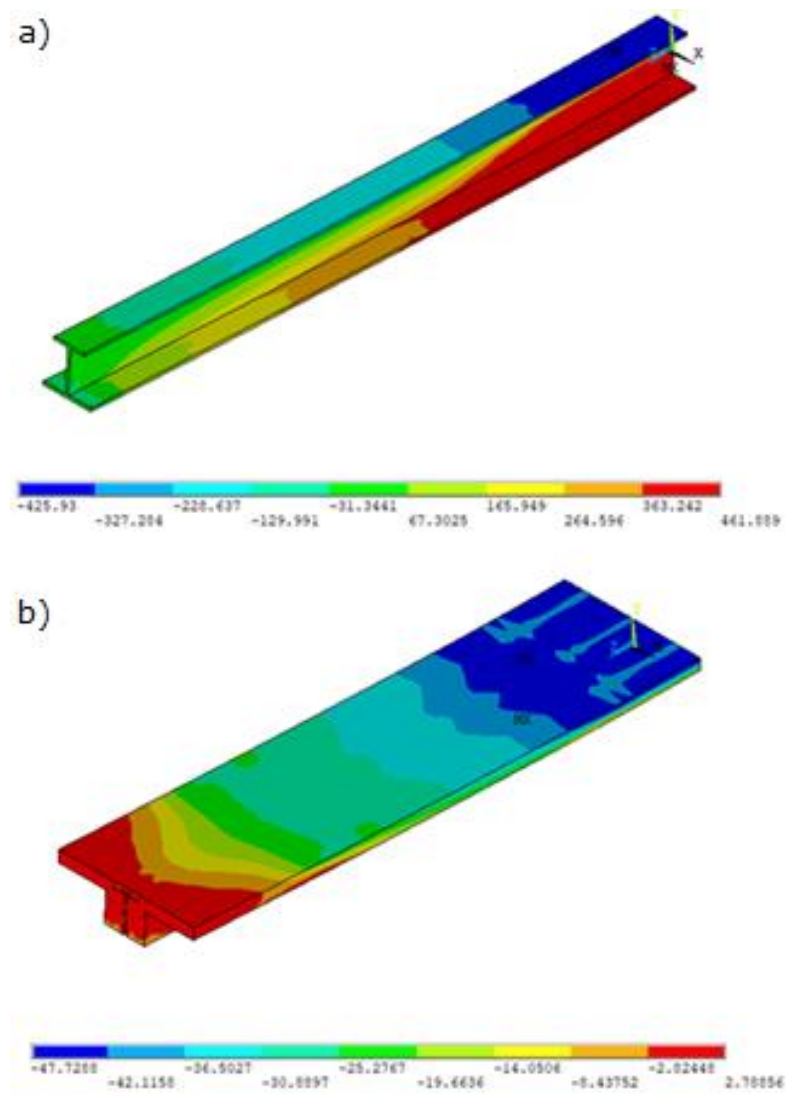

Figura 8. Distribuição de tensões (MPa) no perfil metálico (a) e na laje de concreto (b).

É possível observar que na face superior da laje de concreto, regiões em que se encontram aplicadas as forças que representam a atuação dos atuadores hidráulicos, houve um acúmulo de tensões. Isso ocorre pelo fato de que, embora as cargas tenham sido inseridas em vários nós e acrescidas ao modelo de forma incremental, ocorreu um estado multiaxial de tensões nos elementos finitos.

Em relação às simulações de interface estudadas, ambas apresentaram distribuições de deslizamentos verticais e longitudinais semelhantes. Como mostrado 89 na Figura 9, a consideração da interface por elementos de mola leva a uma diferença entre os deslocamentos entre o perfil metálico e a laje de concreto de aproximadamente $0,15 \mathrm{~mm}$.

Para o modelo com os elementos de contato, a diferença entre o deslocamento longitudinal no aço e no concreto foi de aproximadamente $1,00 \mathrm{~mm}$, Figura 10. Este fato pode ser justificado devido ao modelo composto por elementos de mola ter maiores restrições de deslocamentos aplicadas ao longo da estrutura devido ao acoplamento de deslocamentos nas direções ortogonais ao eixo longitudinal da viga mista.

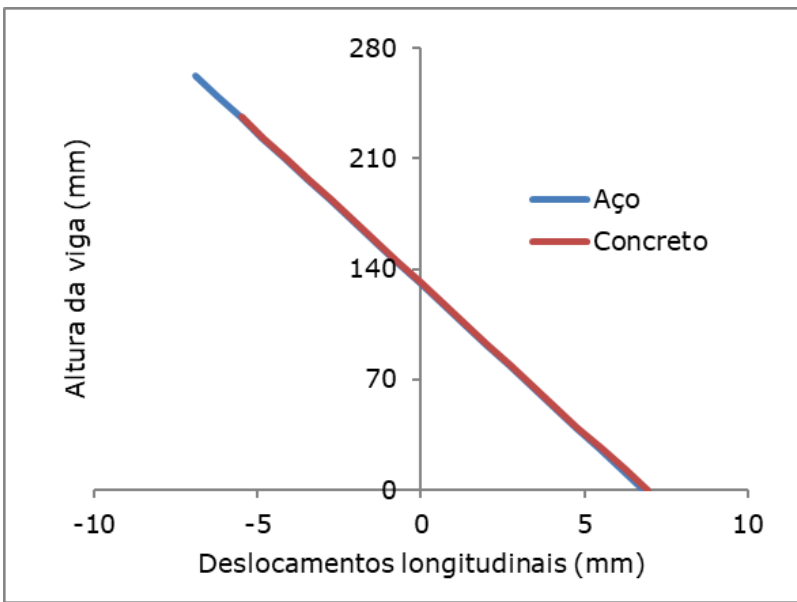

Figura 9. Deslocamentos Iongitudinais do aço e do concreto, em relação ao eixo vertical, com elementos de molas.

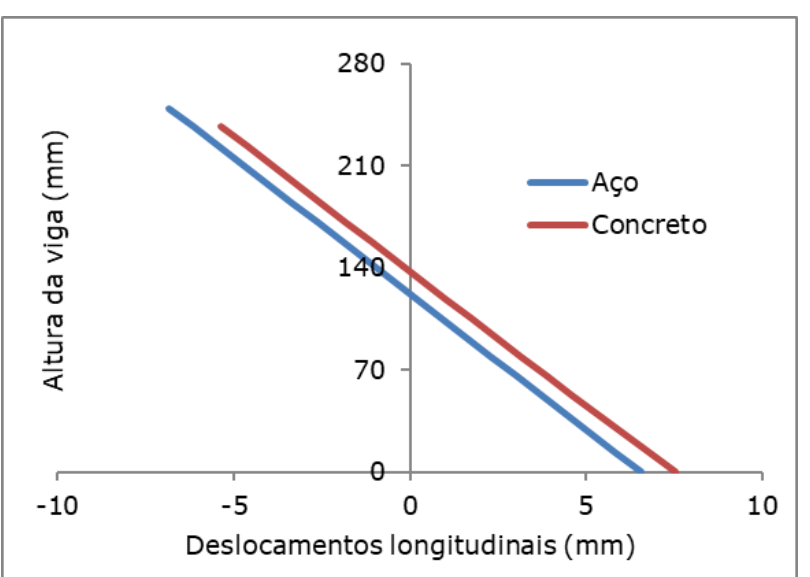

Figura 10. Gráfico dos deslocamentos longitudinais do aço e do concreto, em relação ao eixo vertical, com elementos de contato.

A diferença observada entre os resultados experimentais e numéricos na Figura 7 pode ser motivada pela dificuldade em representar as características do concreto, como o módulo de elasticidade e demais coeficientes, de forma precisa. 
Esta diferença também está associada com o aparecimento das primeiras fissuras do concreto. Além disto, as armaduras foram simuladas sob a forma de taxas. Desta forma, a distribuição de fissuras ocorre de maneira mais intensificada e acelerada no modelo numérico, pois apesar das armaduras não impedirem a ruptura do concreto, elas atuam também no sentido de controle da propagação de fissuras.

O elemento que representa o concreto, SOLID65, tem a capacidade de simular a fissuração do mesmo, em cada passo de carga realizado (ANSYS [15]). As fissuras podem ser sinalizadas através de três diferentes planos em cada elemento. A primeira fissura no elemento é representada por um círculo vermelho, a segunda por um círculo verde e a terceira por um círculo azul [15]. Se a fissura se fechar, é representado um " $x$ " dentro do círculo. Como pode ser visto na Figura 11, com aplicação equivalente a $10 \%$ do carregamento total, é possível notar o aparecimento de algumas fissuras na região onde ocorre a interação entre o aço e o concreto, concentradas no meio do vão.

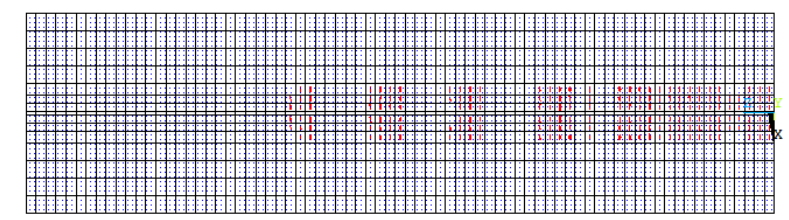

Figura 11. Vista superior da viga com $10 \%$ do carregamento aplicado.

Na Figura 12 é possível observar o avanço da propagação das fissuras ao longo de toda estrutura para $50 \%$ do carregamento aplicado, com aproximação nas duas extremidades do modelo, sendo (a) que representa o extremo da viga, região em que se encontra o apoio; e em (b) a região que representa o eixo central da viga. É observada a partir desta imagem, uma propagação de fissuras na região da capa superior da laje de concreto, proveniente da aplicação das cargas.

Finalmente, com a aplicação completa do carregamento, as fissuras se encontram dispersas por praticamente toda a estrutura, como pode ser visto na Figura $13 \mathrm{com}$ a vista frontal da laje de concreto. Nesta imagem é possível observar o comportamento de fissuras que se abriram e posteriormente se fecharam (representadas por $\mathrm{x}$ dentro do círculo), bem como as fissuras que se mantiveram abertas (círculo sem preenchimento), e por fim, o surgimento de novas fissuras representadas pelas cores verde (segunda fissura) e azul (terceira fissura).

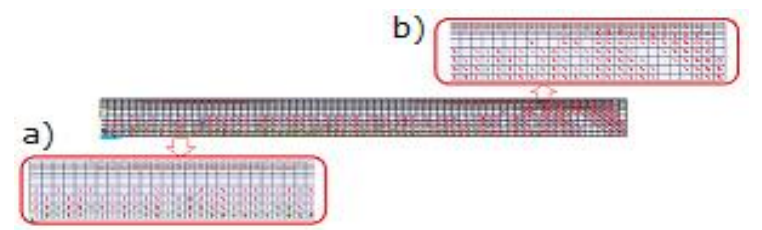

Figura 12. Vista lateral da laje de concreto com 50\% do carregamento total aplicado.

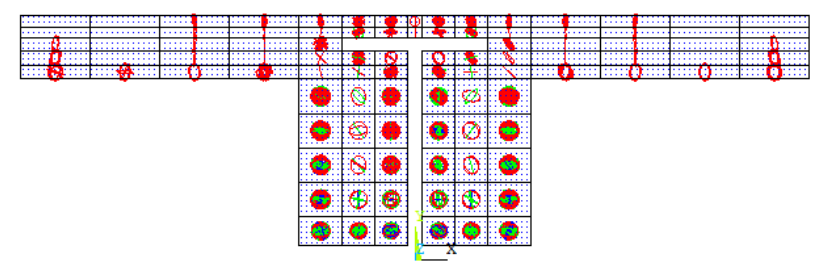

Figura 13. Vista frontal da laje de concreto com o carregamento total aplicado.

\section{Conclusões}

Uma das principais dificuldades na simulação numérica de estruturas mistas é a consideração da interface aço-concreto e da complexidade do comportamento do concreto. Os resultados obtidos neste trabalho para a representação da interação entre $O$ aço e o concreto com elementos finitos de mola (COMBIN39) e de contato (TARGE170 e CONTA173) aproximam-se do resultado experimental, principalmente no trecho linear. Desta forma, obteve-se um modelo satisfatório para a representação de pavimentos mistos de pequena altura. A comparação dos resultados numéricos e experimentais apresentou dispersão entre 5 e $10 \%$. Esta diferença está associada principalmente à representação da fissuração do concreto, que ocorre de maneira mais precoce no modelo numérico quando comparada ao modelo experimental.

É possível supor que estas diferenças sejam ainda possivelmente relacionadas à diferença das propriedades do concreto que se estima para o modelo numérico, como a resistência a tração $\left(f_{c t}\right)$ e o módulo de elasticidade $\left(E_{c}\right)$. Além disso, a representação da interface de maneira aproximada e as condições para viabilizar a modelagem computacional, como a condição de simetria, podem ser fatores que afetam a correlação entre os resultados numéricos e experimentais. Além disso, a representação da malha eletrosoldada através de 
elementos de barra de aço dispersos na laje de concreto pode contribuir significativamente no controle de fissuras.

De forma geral o modelo mostrou-se capaz de representar de forma adequada o complexo comportamento das vigas mistas de pequena altura, considerando duas hipóteses para a simulação da interface aço-concreto, indicando sua viabilidade para a utilização em pesquisas de estruturas mistas açoconcreto.

\section{Referências bibliográficas}

[1] RAMOS, A. L. Análise numérica de pisos mistos aço-concreto de pequena altura. 138 p. Dissertação (Mestrado em Engenharia de Estruturas). Escola de Engenharia de São Carlos, Universidade de São Paulo, São Carlos, 2011.

[2] MALITE, M. Análise do comportamento estrutural de vigas mistas aço-concreto constituídas por perfis de chapa dobrada. 2v. Tese (Doutorado), Escola de Engenharia de São Carlos, Universidade de São Paulo, São Carlos, 1993. [2] TAYLOR, H. F. W. Cement Chemistry, London: Thomas Telford, 2ed, 1997, 459 p.

\section{[3] ASSOCIAÇÃO BRASILEIRA DE NORMAS} TÉCNICAS. NBR 8800. Projeto de estruturas de aço e de estruturas mistas de aço e concreto de edifícios. Rio de Janeiro: ABNT, 2008.

[4] KOCHEM, R. F. F. Modelagem numérica de piso misto de aço e concreto de pequena altura: ênfase à ligação viga-pilar. 107 p. Dissertação (Mestrado em Engenharia de Estruturas). Escola de Engenharia de São Carlos, Universidade de São Paulo, São Carlos, 2018.

[5] HOU, Bingyu. Experimental and Analytical Study of the Shear Transfer in Composite Shallow Cellular Floor Beams. 2012. 316 f. Tese (Doutorado) - School of Engineering and Mathematical Sciences, City University London, Londres, 2012.

[6] LAWSON, R. M.; MULLETT, D. L.; RACKHAM, J. W. Design of Asymmetric Slimflor Beams Using Deep Composite Decking. SCI Publication P175. The Steel Construction Institute, 1997.

[7] PAES, José Luiz Rangel. Aportaciones al Análisis del Comportamiento Estructural de Sistemas Forjados Mixtos Tipo "Slim Floor". 2003. 403 f. Tese 91
(Doutorado) - Programa de Doctorat d'Enginyeria de la Construcció, Universitat Politècnica de Catalunya, Barcelona, Espanha, 2003.

[8] LESKELÄ, M. V.; HOPIA, J. Steel Sections for Composite Shallow Floors. Report RLT 0053E. University of Oulu, Structural Engineering Laboratory. Finlandia, 2000.

[9] LAM, D.; DAI, X.; KUHLMANN, U.; RAICHLE, J.; BRAUN, M. Slim-floor construction - design for ultimate limit state. Steel Construction 8. n. 2. Berlim. 2015.

[10] CHEN, S.; LIMAZIE, T. Composite Slim Floor beams with innovative shear connections. Report RLT 0053E. Proceedings of the ICE - Structures and Buildings. Londres, 2018.

[11] SHEEHAN, T; DAI, X.; YANG, J; ZHOU, K; LAM, D. Flexural behaviour of composite Slim Floor beams. Structure, 21, p. 22-32, 2019.

[12] SCHORR, J., KUHLMANN, U. Design of Slim Flors and their connections between steel and concrete. The 14th Nordic Steel Construction Conference, 2019.

[13] BALDASSINO, N., ROVERSO, G., RANZI, G., ZANDONINI, R. Service and ultimate bahaviour of Slim Floor beam: na experimental study. Structures, 17, p. 74-86, 2019.

[14] ROCHA, F.M., MUNAIAR NETO, ]. Analysis of Slim Floor beams infire: emphasis on the concrete constitutive models. Revista IBRACON de Estruturas e Materiais, 7 n 1, p. 158-177, 2014.

[15] ANSYS. User's Manual for revision 11. Swanson Analysis Systems Inc. Inc., Houston, PA, 2010.

[16] MARCONCIN, L. R. Modelagem numérica de vigas mistas de aço-concreto. Dissertação (Mestrado em Construção Civil) Universidade Federal do Paraná, Curitiba, 2008.

[17] KOTINDA, T. I. Modelagem numérica de vigas mistas aço-concreto simplesmente apoiadas: ênfase ao estudo da interface laje-viga. 120 p. Dissertação (Mestrado em Engenharia de Estruturas). Escola de Engenharia de São Carlos, Universidade de São Paulo, São Carlos, 2006. 
[18] OLIVEIRA, J. P. S.; DIAS J. V. F.; FAKURY, R. H.; CALEZANI A. F. G. Análise numérica da flambagem lateral com distorção em vigas mistas de açoconcreto. CILAMCE 2017.

[19] MODEL CODE 2010. Final draft. Fédération Internacionale du Béton (FIB). Vol. 1. 2012. 